Ladle내 殘留 熔融슬래그의 LF 工程으로 再活用에 관한 研究

中金永煥・劉政珉・金棟植・林鍾動*・楊盛浩*

東國製鋼 中央技術研究所 製鋼研究Team

*東國製鋼 仁川製鋼所 製鋼吕Team

\title{
A Study on the Recycling of Molten Ladle Slag Residue into LF Process
}

\author{
Young-Hwan Kim, Jung-Min Yoo, Dong-Sik Kim, Jong-Hoon Lim* and Sung-Ho Yang* \\ Steel Making Research Team in R\&D center of Dongkuk Steel mill co. \\ *Steel Making Team in Dongkuk Steel mill co., Incheon works.
}

\section{요 약}

전기로 제강공정 중 $\mathrm{LF}$ 공정에서 슬래그는 전기로(EAF)에서 이월된 슬래그와 출강 중에 조재제인 생석회, 돌로마이트 등이 용 강 중에 투입되어 생성된다. $\mathrm{LF}$ 조업이 끝나면 ladle은 연속주조 공정 $(\mathrm{CCM})$ 으로 이송되며, ladle 하부의 노즐을 통해 tundish로 용 강을 내보내어 연속 주조조업을 하게 된다. 일반적으로 연속 주조공정 후 ladle에 남는 슬래그와 잔강(戗鋼)은 슬래그 포트(Pot)에 받아 슬래그 야적장으로 이송되어 파쇄 후 처리된다. 본 연구에서는 연속 주조공정 후 ladle에 잔류한 용융슬래그(线鋼 포함)를 전 기로 출강 후에 ladle 상부에 직접 투입하여 LF 공정 초기의 슬래그를 형성하는데 활용하고자 하였다. 그 결과 LF 공정 중에 사용 되는 생석회의 원단위는 $2.2 \sim 3.2 \mathrm{~kg} / \mathrm{steel-ton}$ 저감되었으며, 용강의 생산회수율은 $0.3 \sim 0.5 \%$ 증가되었다.

주제어 : LF 슬래그, 용융슬래그, $\mathrm{Fe}$ 회수, 슬래그 재활용

\section{ABSTRACT}

LF slag is formed by EAF carryover slag and slag former(such as lime, dolomite) put into the ladle during the tapping molten metal. After LF process, continuous casting is started when molten steel is sent from ladle to tundish through bottom nozzle of ladle. Conventionally, remained molten slag and steel in ladle are poured into a slag port and they are transferred to a slag yard and then recycled. In this study, we investigated about recycling of molten LF slag residue(including Fe residue to reuse) which is made in steelmaking process. As a result, lime usage was decreased about $2.2 \sim 3.2 \mathrm{~kg} / \mathrm{steel}$-ton and also molten steel yield rate was increased about $0.3 \sim 0.5$ percent point.

Key Word : LF slag, Molten slag, Fe recovery, Slag recycling
1. 서 론
감이 환경 친화적 측면에서 핵심 과제로 대두되고 있으
최근 철강업에서는 $\mathrm{CO}_{2}$ 저감과 슬래그 발생율의 저
며, 제강공정에서 배출된 슬래그를 재활용하여 부가가 치를 창출하고자 많은 연구가 진행되어 왔다. 그러나,

\footnotetext{
* Received : September 28, $2012 \cdot$ Revised : November 15, $2012 \cdot$ Accepted : November 26, 2012

*Corresponding Author : Young-Hwan Kim (E-mail: younghwan2.kim@dongkuk.com)

Steel Making Research Team, R \& D Center of Dongkuk Steel Mill. Co., 440 Songdong-ri, Daesong-myeon, Nam-gu, Pohang city, Gyeongbuk, 790-841 Korea.

Tel : +82-54-271-2721 / Fax : +82-2-317-9062

(C) The Korean Institute of Resources Recycling. All rights reserved. This is an open-access article distributed under the terms of the Creative Commons Attribution Non-Commercial License (http://creativecommons.org/licenses/by-nc/3.0/), which permits unrestricted non-commercial use, distribution and reproduction in any medium, provided the original work is properly cited.
} 
생성된 슬래그를 제강 공정간에 재사용하여 원천적으로 슬래그의 발생량을 저감하는 것이 보다 우선적으로 검 토되어야 한다.

일반적으로 국내에서 전기로 슬래그는 거의 제강공정 간에 재활용되지 못하고 슬래그 야드에 야적되어 주로 골재로 사용되고 있는 실정이며, 특수강 제조시 $\mathrm{LF}$ (Ladle furnace) 슬래그는 $\mathrm{CaO}$ 성분이 높아 고화재 나 전기로에서 $\mathrm{CaO}$ 품위가 낮은 조재제로 재사용되고 있다. 그러나 일반강을 제조하는 전기로 업체에서 발생 된 $\mathrm{LF}$ 슬래그는 $\mathrm{CaO}$ 함량이 높지 않아, 다른 용도로 재활용되지 못하고 있는 실정이다. 종래에는 $\mathrm{LF}$ 공정에 서 재활용되지 않고 수 heats의 용융 ladle 잔류 슬래 그를 슬래그 pot에 담아 슬래그 야드장으로 이송하여 냉각시킨 후, 地金을 분리하고 슬래그는 파쇄하여 골재 등 부가가치가 낮은 용도로 활용하였으며 地金은 전기 로로 다시 투입하여 활용하였다.

용융 ladle 슬래그의 제강 공정간에서의 활용에 관한 연구 사례1)는 $\mathrm{BOF}$ slag로의 활용에 대해 최근 진행된 바 있으며, 탈황과 탈인에 부정적인 효과는 없고, 생석 회 원단위를 $2 \mathrm{~kg} / \mathrm{t}$-steel 저감하는 효과를 얻었다. 또한 $\mathrm{LF}$ 공정으로의 활용은 잔류 용융슬래그에 대해 기화 탈 황을 실시한 후 탈황제로 사용하는 방법의 사례 ${ }^{2)}$ 가 조 사되었다.

현재 일부 제강사에서는 현장에서 일부 용융 상태의 $\mathrm{LF}$ 슬래그를 $\mathrm{LF}$ 초기 슬래그 조재제로 활용하고 있으 나 정량적인 효과의 분석결과가 발표된 사례는 없고, 조 업 라인상의 간섭이 있을 경우 재활용을 시도할 수 없 으며, ladle 이동에 간섭을 받지 않아 재활용이 가능한 경우에도 공정간 timing이 맞지 않는 경우에도 재활용 을 할 수 없어 재활용율은 낮아지게 된다.

본 연구에서는 연속주조 공정후 ladle에 남은 용융상태 의 슬래그를 LF 초기 슬래그 형성을 위한 조재제로 직접 활용하고자 하였으며, 이에 따른 조업 영향성을 조사하였다.

\section{2. 실험방법}

전기로 제강 공정은 일반적으로 전기로, ladle furnce
(LF), 연속주조(Continuous Casting)로 크게 구분되며, 전체 조업 공정에 대한 흐름을 Fig. 1에 나타내었다. 전기로에서 용해된 용강은 ladle에 tapping되며 이때 일 부 전기로 슬래그가 ladle로 이월된다. 수강(受鋼)된 ladle 은 $\mathrm{LF}$ 공정으로 이송되며, $\mathrm{LF}$ 조업을 거쳐 tundish로 용강을 받아 연속 주조가 이루어진다. ladle의 상부에 존 재하는 슬래그는 용강의 청정성을 유지하기 위해 tundish 로 유출되지 않고, ladle에 남긴 후 슬래그 pot로 배출되 며 일부의 地金이 슬래그와 함께 잔류하게 된다.

연속주조 공정에서 잔류되는 ladle 용융슬래그의 LF 공정으로의 재활용 조업은 일반 철근 $(\mathrm{SD} 300, \mathrm{SD} 400$ 등)제품을 생산하는 당사 $100 \mathrm{~T}$ 전기로(인천)에서 실시 하였다.

\section{1. 일반강 조업에서 LF 슬래그 성분}

재활용을 실시하지 않은 일반 조업의 ladle 슬래그의 성분 함량은 $\mathrm{LF}$ 도착시와 $\mathrm{LF}$ 출강시에 슬래그 샘플을 10 개씩 채취하고 평균하여 Table 1에 나타내었다. LF 슬래그의 정량분석은 X-선 형광분석기(XRF, S8-Tiger, Bruker)를 사용하여 실시하였다. $\mathrm{LF}$ 도착 슬래그의 $\mathrm{CaO}$ 함량은 약 $32 \%$ 이며, $\mathrm{LF}$ 공정간 생석회를 $300 ~ 400 \mathrm{~kg} /$ heat 정도 투입하기 때문에 $\mathrm{LF}$ 출강시의 슬래그 성분은
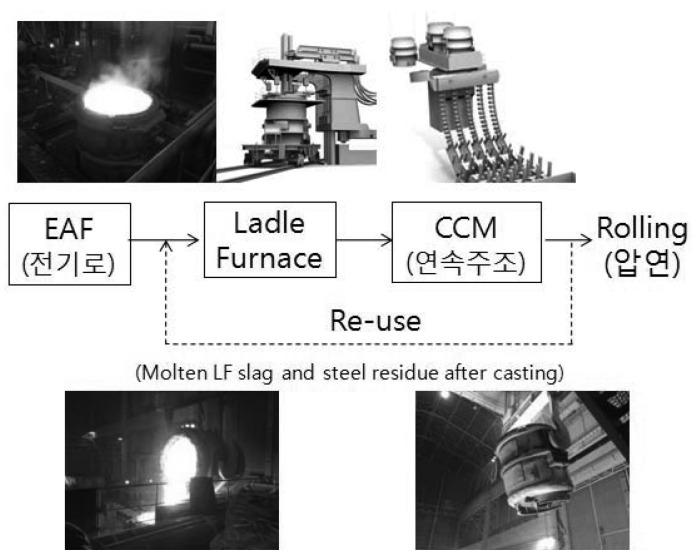

Fig. 1. Schematic diagram of recycling for the remained molten slag and steel in LF after continuous casting.

Table 1. Composition of LF slag for common steel making

\begin{tabular}{|c|c|c|c|c|c|c|c|}
\hline Component & $\mathrm{CaO}$ & $\mathrm{SiO}_{2}$ & $\mathrm{Al}_{2} \mathrm{O}_{3}$ & $\mathrm{MgO}$ & $\mathrm{MnO}$ & $\mathrm{FeO}$ & $\mathrm{P}_{2} \mathrm{O}_{5}$ \\
\hline LF start & 31.58 & 28.47 & 9.67 & 12.89 & 7.06 & 4.73 & 0.26 \\
\hline LF finish & 41.74 & 28.07 & 12.39 & 13.24 & 0.57 & 0.49 & 0.29 \\
\hline
\end{tabular}


$\mathrm{CaO}$ 의 함량이 약 $42 \%$ 정도로 $10 \%$ 정도 높은 값을 보 였다.

\section{2. 재활용 방법}

용융 ladle 슬래그의 재활용 방법은 Fig. 1에 점선으 로 표시한 것과 같이, 연주 tundish로 용강을 주입한 후 잔류한 ladle내의 용융슬래그를 crane을 이용하여 전 기로에서 출강된 용강과 이월된 슬래그가 포함된 ladle 위에 기울여 부어서 혼탕한 후 $\mathrm{LF}$ 공정으로 투입한다. 재활용 조업시에는 ladle 슬래그의 $\mathrm{CaO}$ 성분 함유를 고려하여, $\mathrm{LF}$ 공정간 생석회 $(\mathrm{CaO}$ 함량 $90 \%$ 이상 $)$ 투입 량을 약 $200 \sim 300 \mathrm{~kg} / \mathrm{heat}$ 정도 줄여 통상적으로 조업 을 행하였다.

\section{3. 실험결과}

용융 ladle 슬래그의 LF 공정으로의 재활용율은 2012년 3월에 32\%로 시작해서 6월에 58\%정도로 증대 되었다. 지난 3 개월 $(4 \sim 6$ 월 $)$ 의 조업실적을 통해 재활용 전후의 조업 영향성을 평가하였다.

\section{1. 재활용 후 LF 슬래그 성분 변화}

용융 ladle 슬래그를 LF 초기 조업시 투입한 후 $\mathrm{LF}$ 도착과 출강시점에서 3 회 이상 채취하여 정량분석을 실 시하고 성분 함량을 평균하여 Table 2에 나타내었다.

$\mathrm{LF}$ 도착 슬래그 중 $\mathrm{FeO}$ 와 $\mathrm{MnO}$ 는 전기로 출강 후 ladle에 용융 ladle슬래그가 혼합함에 따라 희석되고 일부 는 용강중의 $\mathrm{Si}$ 과 환원반응이 일어나 $2 \sim 5 \%$ 정도 낮아 졌으며, $\mathrm{CaO}$ 와 $\mathrm{Al}_{2} \mathrm{O}_{3}$ 함량은 $1 \sim 5 \%$ 정도 증가하였다.

재활용 전 전기로 출강 슬래그 성분, 출강시 조재제와 합금철 투입량을 통해서 재활용 후 LF 도착시 슬래그 성 분 함량이 산출되도록 물질수지를 Factsage 프로그램으로 계산한 결과, 전기로 슬래그의 ladle로의 이월량은 $2.0 \mathrm{ton}$ 으로 계산되었다. 또한 용융 ladle 슬래그의 재활용 양은 재활용한 후 $\mathrm{LF}$ 도착 슬래그 성분 함량이 구해지도록 Factsage 프로그램으로 계산하였으며, 그 결과 용융 ladle 슬래그의 재활용 양은 1.5 ton으로 계산되었다.
전기로에서 출강후 ladle에 용융 ladle 슬래그를 혼합 투입하면 초기에 생석회의 재화(슬래그 화)를 촉진시킬 수 있고, 저융점의 슬래그가 용강이 대기중에 노출되지 않도록 함으로써 용강중의 $\mathrm{Si}, \mathrm{Mn}$ 의 재산화를 방지할 수 있다. 또한 조기에 형성된 슬래그 중 $\mathrm{FeO}$ 와 용강중 의 $\mathrm{Si}, \mathrm{Mn}$ 이 반응하여 $(\mathrm{FeO})$ 의 환원 반응이 일어날 것으로 판단된다.

아래 식 $(1) \sim(3)$ 에 $[\mathrm{Si}],[\mathrm{Mn}]$ 과 $(\mathrm{FeO}),(\mathrm{MnO})$ 와의 반응식과 $1,600^{\circ} \mathrm{C}$ 온도에서 $\mathrm{Gibbs}$ 표준 자유에너지 계산 값을 나타내었으며, 이를 통해 용강 중 $\mathrm{Si}$ 의 $(\mathrm{FeO})$ 와의 반응이 $\mathrm{Mn}$ 보다 우선적으로 일어남을 알 수 있다.

$$
\begin{array}{cc}
{[\mathrm{Si}]+2(\mathrm{FeO}) \rightarrow} & \left(\mathrm{SiO}_{2}\right)+2[\mathrm{Fe}] \\
\Delta \mathrm{G}^{\mathrm{o}}=-279.4 \mathrm{~kJ} / \mathrm{mol} \\
{[\mathrm{Mn}]+(\mathrm{FeO}) \rightarrow} & (\mathrm{MnO})+[\mathrm{Fe}] \\
\Delta \mathrm{G}^{\mathrm{o}}=-88.0 \mathrm{~kJ} / \mathrm{mol} \\
{[\mathrm{Si}]+2(\mathrm{MnO}) \rightarrow} & \left(\mathrm{SiO}_{2}\right)+2[\mathrm{Mn}] \\
\Delta \mathrm{G}^{\mathrm{o}}=-103.4 \mathrm{~kJ} / \mathrm{mol}
\end{array}
$$

$\mathrm{LF}$ 출강 슬래그와 재활용하기 전의 $\mathrm{LF}$ 도착 슬래그 의 성분 함량을 단순히 합산하면 재활용 후 LF 도착 슬 래그 성분이 계산되지는 않았다. 그 이유는 위와 같이 용 강중의 $\mathrm{Si}$ 과 $\mathrm{Mn}$ 의 산화 및 $(\mathrm{FeO})$ 와 $(\mathrm{MnO})$ 의 환원에 의해 발생하기 때문이며, 화학양론적으로 물질수지를 계 산한 결과 $\mathrm{Si}$ 는 $0.27 \mathrm{ton} / \mathrm{heat}, \mathrm{Mn}$ 은 $0.04 \mathrm{ton} / \mathrm{heat}$ 이 산화 되었으며 $(\mathrm{FeO})$ 는 $0.49 \mathrm{ton} / \mathrm{heat}$ 이 환원된 것으로 계산되 었다. 용융 ladle 슬래그의 재활용에 따른 LF 도착 슬래 그 성분 함량의 계산값과 분석값을 Table 3에 나타내었 으며, 계산값과 분석값은 거의 일치하는 값을 보였다.

용융 ladle 슬래그의 재활용에 따른 슬래그 성분 변화는 Fig. 2에 나타낸 것과 같이 $\mathrm{CaO}-\mathrm{SiO}_{2}-\mathrm{Al}_{2} \mathrm{O}_{3}-\mathrm{MgO}(15 \%) 4$ 원계 상태도에 표시하였다. 4원계 상태도는 열역학 계산 소프트웨어인 Factsage 프로그램을 사용하여 도시하였다.

재활용 전의 $\mathrm{LF}$ 도착 슬래그와 출강 슬래그의 상태 도 상에서의 융점은 $1,600^{\circ} \mathrm{C}$ 이상을 나타내었으며, 용 융 ladle 슬래그를 ladle이 LF 도착 전에 투입하여 혼 합함에 따라, $\mathrm{Al}_{2} \mathrm{O}_{3}$ 성분 함량이 증가하면서 슬래그 조

Table 2. Composition of LF slag after recycling the molten ladle slag into LF process

\begin{tabular}{|c|c|c|c|c|c|c|c|}
\hline Component & $\mathrm{CaO}$ & $\mathrm{SiO}_{2}$ & $\mathrm{Al}_{2} \mathrm{O}_{3}$ & $\mathrm{MgO}$ & $\mathrm{MnO}$ & $\mathrm{FeO}$ & $\mathrm{P}_{2} \mathrm{O}_{5}$ \\
\hline LF start & 34.91 & 29.42 & 10.89 & 13.38 & 4.77 & 1.76 & 0.26 \\
\hline LF finish & 36.75 & 29.51 & 11.70 & 13.89 & 0.78 & 0.41 & 0.27 \\
\hline
\end{tabular}


Table 3. Comparison between analysized and calculated slag compositions after recycling

$(\operatorname{mass} \%)$

\begin{tabular}{|c|c|c|c|c|c|c|c|}
\hline & $\mathrm{CaO}$ & $\mathrm{SiO}_{2}$ & $\mathrm{Al}_{2} \mathrm{O}_{3}$ & $\mathrm{MgO}$ & $\mathrm{MnO}$ & $\mathrm{FeO}$ & $\mathrm{P}_{2} \mathrm{O}_{5}$ \\
\hline Analysis & 34.91 & 29.42 & 10.89 & 13.38 & 4.77 & 1.76 & 0.26 \\
\hline Calculation & 34.58 & 29.40 & 11.27 & 13.73 & 4.52 & 1.64 & 0.25 \\
\hline
\end{tabular}

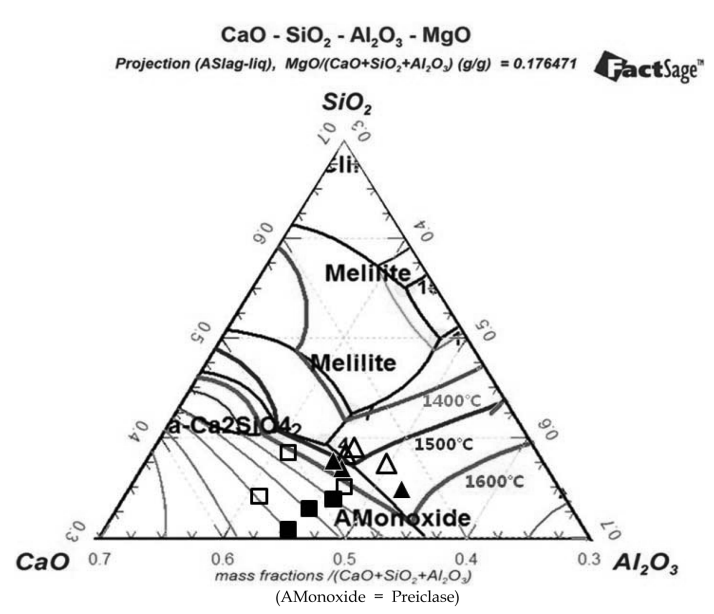

Fig. 2. Phase diagram of $\mathrm{CaO}-\mathrm{SiO}_{2}-\mathrm{Al}_{2} \mathrm{O}_{3}(\mathrm{MgO} 15 \%$ ), symbols represent LF slag composition (Berfore recycling ladle slag : LF start $\square \rightarrow$ LF finish $\mathbf{\square}$, after recycling ladle slag : LF start $\triangle \rightarrow$ LF finish $\boldsymbol{\Delta}$ ).

성이 저융점 구역으로 이동되었으며, 융점은 $1,500^{\circ} \mathrm{C}$ 이하에 해당된다. 또한 $\mathrm{LF}$ 출강 슬래그의 융점도 $1,500 \sim 1,600^{\circ} \mathrm{C}$ 사이에 위치함에 따라 저융점 슬래그가 형성되었음을 알 수 있다.

\section{2. 재활용에 따른 조업 영향성 평가}

\subsection{1. 생석회 투입량 및 LF 슬래그 배출량}

용융 ladle 슬래그는 LF 조업간 생석회 투입으로 인 해 $\mathrm{CaO}$ 原이 $\mathrm{LF}$ 도착 슬래그보다 높아 재활용시 $\mathrm{LF}$ 공정에서 생석회 투입량을 저감할 수 있을 것으로 예상 되어, $\mathrm{LF}$ 공정에서 생석회 투입량을 저감하였다. 재활 용을 실시함에 따라 LF 공정에서 생석회 투입 원단위 는 $2.2 \sim 3.2 \mathrm{~kg} /$ ton-steel 저감이 가능하였다. 그러나 $\mathrm{LF}$ 공정에서 생석회 투입량을 줄임으로 인해 $\mathrm{LF}$ 출강 슬 래그 중 $\mathrm{CaO}$ 의 함량이 낮아져 재활용시 $\mathrm{CaO}$ 原이 부 족하다고 판단되어, $\mathrm{LF}$ 공정간 생석회의 투입량을 적정 화하도록 하였다. 이와 같은 ladle 슬래그의 재활용을 통해 $\mathrm{LF}$ 공정간 생석회 투입량을 $2.2 \mathrm{~kg} /$ ton-steel 이상 저감할 수 있으며, 연간 1,276 ton의 생석회 투입량을 저감할 수 있게 되었다. 한편, LF 환원 슬래그의 배출

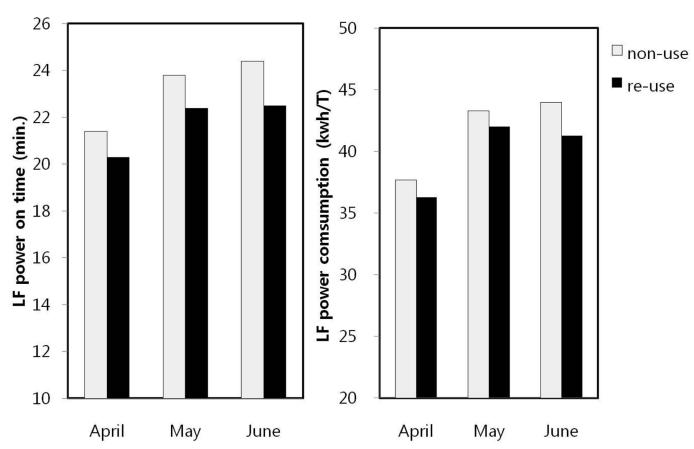

Fig. 3. Change of LF electric power consumption and power on time with recycling of molten ladle slag into LF.

량은 종래의 전체 $\mathrm{LF}$ 환원슬래그 배출량의 약 $26 \%$ 를 줄일 수 있게 되었다.

\subsubsection{LF 전력원단위 및 조업시간}

$\mathrm{LF}$ 슬래그 재활용에 따른 $\mathrm{LF}$ 전력 원단위 및 조업 시간 변화를 Fig. 3에 나타내었다. LF 조업시간은 재활 용을 실시함에 따라 단축되었고 2012년 6월의 경우 $7.8 \%(24.4 \rightarrow 22.5$ 분) 감소한 결과를 얻었다. 또한 $\mathrm{LF}$ 전력 원단위는 재활용을 실시함에 따라 저감되었고 2012년 6월 실적으로 $6.1 \%(44.0 \rightarrow 41.3 \mathrm{kwh} / \mathrm{ton})$ 개선 되었다.

용융 ladle 슬래그는 $1,500^{\circ} \mathrm{C}$ 이상의 용융상태로 $\mathrm{LF}$ 도착 전에 혼합 투입함에 따라 LF에 도착되는 슬래그의 재화가 촉진된다. LF 공정간 고체 상태의 생석회 투입을 줄임에 의해 용해에 필요한 에너지를 저감하고, 융융상 태의 슬래그를 투입함에 따라 용융상태의 슬래그가 가 지고 있는 현열에 의해 $\mathrm{LF}$ 공정간 전력 원단위가 저감 되고 조업 시간이 단축되었다고 판단된다.

3.2.3. 제강 회수율, 합금성분 $(\mathrm{Si}, \mathrm{Mn})$ 의 회수율 변화 일반적으로 전기로 제강 회수율은 생산량을 스크랩 장입량으로 나누어 평가한다. 용융 ladle 슬래그를 LF 로 재활용하기 전과 후의 제강 회수율의 변화를 Fig. 4 에 나타내었다. 제강 회수율은 슬래그 재활용에 따라 4 


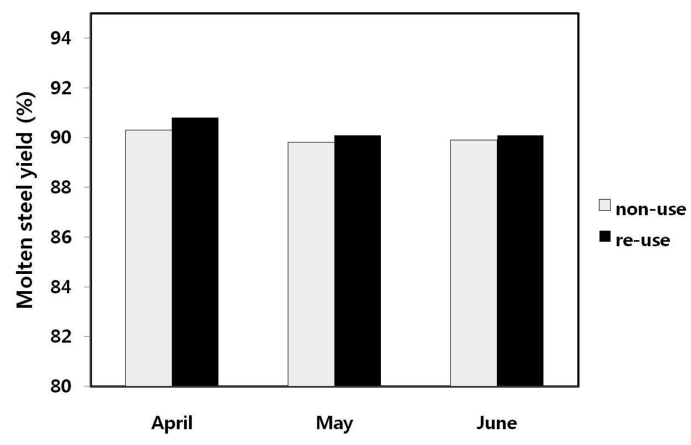

Fig. 4. Molten steel yield change with recycling of molten ladle slag into LF.

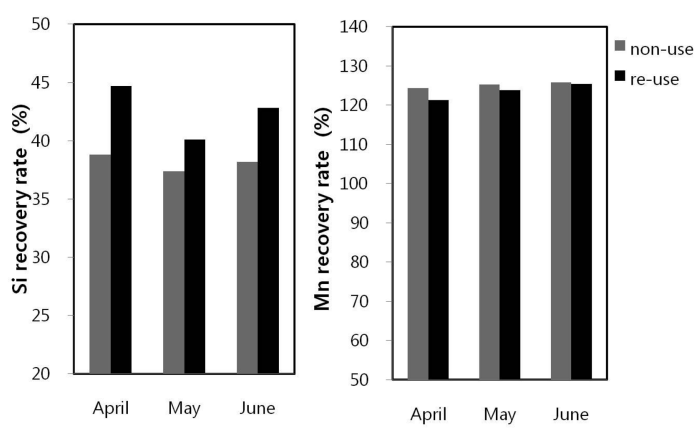

Fig. 5. Change of $\mathrm{Si}, \mathrm{Mn}$ recovery rate with addition of molten ladle slag into LF.

월에 $90.3 \%$ 에서 $90.8 \%$ 로 $0.5 \% \mathrm{p}$ 증가하였으며, 5 월과 6 월에는 각각 $0.3 \% \mathrm{p}, 0.2 \% \mathrm{p}$ 씩 증가하였다.

이와 같은 제강회수율의 차이는 다음과 같은 원인에 의해 발생한다고 판단된다. 재활용을 하기 전의 종래 방 식은 용융 ladle 슬래그를 數回 정도 슬래그 포트에 받 아 슬래그 야드장으로 이송하여 부은 후 냉각하여 地金 을 분리 회수하고 있으며, 용융상태의 슬래그와 地金을 함께 붓기 때문에 서로 섞여 분리 회수하기가 어려워 ${ }^{3)}$ 地金 회수율이 저하되었다. 그러나 용융 상태의 슬래그 와 地金를 LF 슬래그로 혼합 투입시에는 분리 회수 손 실이 줄어들고, 地金이 대부분 회수되어 전체 제강 회 수율이 상승된 것으로 판단된다.

전기로 제강 공정 중 합금철 투입에 의한 $\mathrm{Si}$ 과 $\mathrm{Mn}$ 성 분의 회수율은 (용강 중 $\mathrm{Si}, \mathrm{Mn}$ 原의 함량 $(\mathrm{kg})) /($ 합금 철에 의해 투입된 $\mathrm{Si}, \mathrm{Mn}$ 原의 량 $(\mathrm{kg})) \times 100$ 으로 나타 낼 수 있다. 용강 중 $\mathrm{Si}$ 과 $\mathrm{Mn}$ 의 原의 함량은 연속주조 시 용강의 $\mathrm{Si}$ 과 $\mathrm{Mn}$ 의 성분 함량을 출강량에 곱해 계산 하고, 실제 조업 중에 투입된 $\mathrm{Fe}-\mathrm{Si}$ 과 $\mathrm{Si}-\mathrm{Mn}, \mathrm{Fe}-\mathrm{Mn}$ 중 의 $\mathrm{Si}$ 와 $\mathrm{Mn}$ 의 原을 투입량으로 계산한다. 재활용 전후의
$\mathrm{Si}$ 과 $\mathrm{Mn}$ 의 회수율 변화는 Fig. 5 에 나타내었다. $\mathrm{Si}$ 회수 율은 ladle 슬래그 재활용 후 $4.6 \sim 7.9 \%$ 증가하는 결과 를 나타내었으며, $\mathrm{Mn}$ 회수율은 ladle 슬래그 재활용 전 과 유사한 수준을 보였다.

이와 같이 $\mathrm{Si}$ 회수율이 증가하는 이유는 용융 ladle 슬래그를 혼합함에 따라 용강 상부에 저융점의 슬래그 층을 형성하여 용강의 산화가 방지되었기 때문으로 판 단된다. $\mathrm{Mn}$ 회수율은 $100 \%$ 를 상회하는 값을 보이는데 이는 용강중의 $\mathrm{Si}$ 가 슬래그 중의 $\mathrm{MnO}$ 와 반응하여 $\mathrm{Mn}$ 이 용강으로 환원회수되는 復 $\mathrm{Mn}$ 이 이루어지기 때문이 며, 재활용에 따른 $\mathrm{Mn}$ 회수율의 저하는 ladle 슬래그의 혼합에 따라 슬래그 중 $\mathrm{FeO}$ 와 $\mathrm{MnO}$ 가 희석되는 효과 에 의해 용강과 슬래그 계면에서 $(\mathrm{MnO}) /[\mathrm{Mn}]$ 비가 상 대적으로 줄어 환원속도가 감소)된 것으로 판단된다.

\subsubsection{Sulfur 함량의 변화}

Ladle 슬래그의 재활용에 따라 LF 출강후 연속주조 시 용강중의 Sulfur의 함량은 2012년 6월에 재활용 전 $278 \mathrm{ppm}$ 에서 재활용 후 $298 \mathrm{ppm}$ 으로 다소 증가(20ppm) 하는 결과를 나타내었다. 이는 $\mathrm{LF}$ 조업간 생석회 투입량 을 2.2 3.2kg/ton-steel로 저감함에 따라 LF 슬래그 중 $\mathrm{CaO}$ 함량이 줄어들었으며, 이를 재활용함에 의해 $\mathrm{CaO}$ 原 이 재활용 이전 만큼 증가하지 않았기 때문이다.

일반적으로 슬래그의 염기도 $\left(\mathrm{CaO} / \mathrm{SiO}_{2}\right)$ 가 높을수록 $\mathrm{LF}$ 공정간 탈황율은 증가한다고 알려져 있다.5) 본 실험 에서 슬래그의 염기도는 재활용 이전에 비해 상대적으 로 낮아져서 탈황율은 다소 저하되고, 이미 탈황에 사 용된 슬래그에 탈황 생성물인 $\mathrm{CaS}$ 가 일부 형성되어 재 활용하였을 때 탈황능이 약간 감소된 것으로 사료된다. 그러나 일반강 철근 제조공정에서 Sulfur의 상한 기준 치는 $400 \mathrm{ppm}$ 이며, Sulfur의 함량이 다소 증가하여 조 정이 필요한 경우 $\mathrm{LF}$ 공정에서 생석회 투입량 제어로 대처가 가능한 것으로 판단된다.

\section{4. 결 론}

전기로 제강공정 중 용융 ladle 잔류슬래그를 $\mathrm{LF}$ 조 업시작 전 ladle에 직접 혼합 투입하여 재활용 실험을 수행하였으며, 재활용 조업과 미실시 조업에 대해 서로 비교 분석하여 그 효과를 조사한 결과 다음과 같은 결 론을 얻었다.

1) $\mathrm{CaO}$ 原을 포함하는 용융 ladle 슬래그를 혼합 사 용함에 의해 $\mathrm{LF}$ 공정간 생석회의 투입은 $2.2 \sim 3.2 \mathrm{~kg} /$ 
ton-steel 저감이 가능하였다.

2) 용융상태의 현열을 가진 고온 슬래그를 혼합사용 하고, $\mathrm{LF}$ 공정에서 고체 상태의 생석회 투입량을 저감 함에 따라 $\mathrm{CaO}$ 의 용해에 필요한 에너지 소모량이 줄어 들어, $\mathrm{LF}$ 전력원단위는 $1.4 \sim 2.7 \mathrm{kwh} / \mathrm{t}$ 이 저감 가능하 였고, 조업시간은 $1.1 \sim 1.9$ 분/heat을 단축하는 효과를 얻 었다.

3) 제강 회수율은 LF 슬래그를 재활용함에 의해 $0.2 \sim 0.5 \%$ 증가됨을 보이는데, 이는 종래의 냉각 후 파 쇄하고 슬래그와 地金을 분리 회수방식보다는 용융상태 로 직접 재사용하기 때문에 Metal의 회수율이 증가된 것으로 판단된다.

4) 재활용 후 제강 공정간 $\mathrm{Si}$ 의 회수율은 $4.6 \sim 7.9 \%$ 까지 증가하였으며, $\mathrm{Mn}$ 회수율은 유사한 수준을 보였 다. $\mathrm{Si}$ 회수율의 증가는 $\mathrm{LF}$ 도착 전에 저융점 슬래그 를 형성함에 의해 용강의 산화가 방지되었기 때문으로 사료된다.

\section{참고문헌}

1. A. Dahlin, A. Tilliander, J. Eriksson and P. G. Jo"nsson, 2012 : Influence of ladle slag additions on BOF process performance, Ironmaking \& Steelmaking, Vol. 39, No. 5,

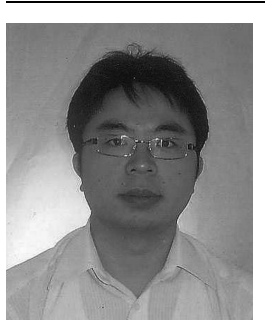

\section{金 永 煥}

• 전북대학교 금속공학과 공학박사

- 전북대학교 신소재공학부 조교

- 현재 동국제강 중앙기술연구소 제강 연구팀 책임연구원

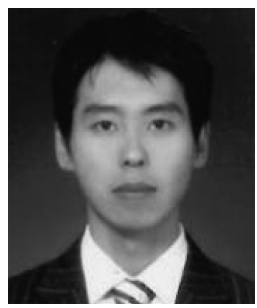

\section{劉 政 珉}

- 인하대학교 대학원 금속공학과 석사

- 현재 동국제강 중앙기술연구소 제강 연구팀 전임연구원 pp. 378-385.

2. Korean Patent, 2002 : "Sulfur reduction method of molten slag in electirc arc furnace steelmaking process", Pat. No. 2002-0047574.

3. Jong Yeong Hyun, Hyung Suk Kim, Kang Ho Shin, Dong Sung Cho, 1994 : A Study on the recovery of a metal from the steelmaking E.A.F slag, Proceedings of the International Symposium on Resource Conservation and Environmental Technologies in Metallurgical Industries, pp. 526-532.

4. Ho-Snag Sohn, Jeong-Sik Kim and Zhao-Ping Chen, 1999 : Effect of Iron Compositions on Reduction Kinetics of Manganese Oxide in $\mathrm{CaO}-\mathrm{SiO}_{2}$-MgOsat.-FeO-MnO Slag, Vol. 37, No. 7, pp. 872 877.

5. Yoshio Shimokawa, 1948 : Desulfurization of Basic OpenHearth Steel, The Iron and Steel Institute of Japan, pp. 46-51.
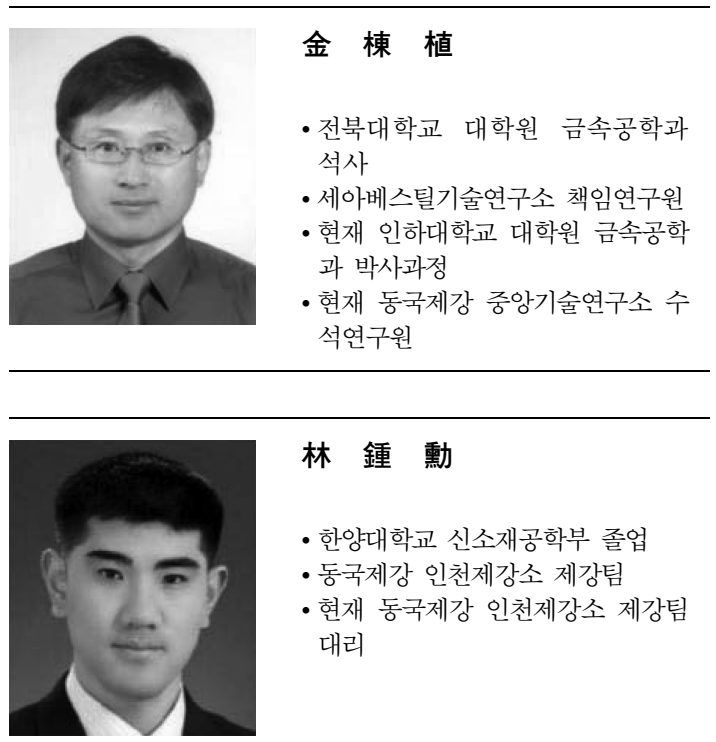

\section{林 鍾 勳}

- 한양대학교 신소재공학부 졸업 • 동국제강 인천제강소 제강팀

- 현재 동국제강 인천제강소 제강팀 대리

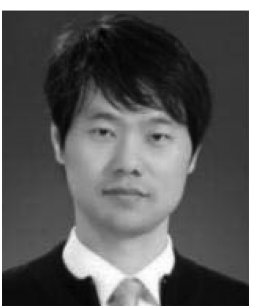

楊 盛 浩

• 동아대학교 기계공학과 졸업

- 현재 동국제강 인천제강소 제강팀 차창 